\title{
Elongator subunit 3 positively regulates plant immunity through its histone acetyltransferase and radical S-adenosylmethionine domains
}

\author{
Christopher T DeFraia ${ }^{1,3+}$, Yongsheng Wang ${ }^{1+}$, Jiqiang $\mathrm{Yao}^{2}$ and Zhonglin Mou ${ }^{1 *}$
}

\begin{abstract}
Background: Pathogen infection triggers a large-scale transcriptional reprogramming in plants, and the speed of this reprogramming affects the outcome of the infection. Our understanding of this process has significantly benefited from mutants that display either delayed or accelerated defense gene induction. In our previous work we demonstrated that the Arabidopsis Elongator complex subunit 2 (AtELP2) plays an important role in both basal immunity and effector-triggered immunity (ETI), and more recently showed that AtELP2 is involved in dynamic changes in histone acetylation and DNA methylation at several defense genes. However, the function of other Elongator subunits in plant immunity has not been characterized.

Results: In the same genetic screen used to identify Atelp2, we found another Elongator mutant, Atelp3-10, which mimics Atelp2 in that it exhibits a delay in defense gene induction following salicylic acid treatment or pathogen infection. Similarly to AtELP2, AtELP3 is required for basal immunity and ETI, but not for systemic acquired resistance (SAR). Furthermore, we demonstrate that both the histone acetyltransferase and radical S-adenosylmethionine domains of AtELP3 are essential for its function in plant immunity.

Conclusion: Our results indicate that the entire Elongator complex is involved in basal immunity and ETI, but not in SAR, and support that Elongator may play a role in facilitating the transcriptional induction of defense genes through alterations to their chromatin.
\end{abstract}

Keywords: Arabidopsis, Elongator, Plant immunity, AtELP3, Transcription

\section{Background}

Plants possess an innate immune system that protects them from microbial pathogens, but lack the adaptive immunity of mammals $[1,2]$. Each plant cell is capable of sensing non-self entities and mounting immune responses, demonstrating remarkable functional plasticity. Recognition of pathogen-associated molecular patterns (PAMPs) results in PAMP-triggered immunity (PTI) that prevents pathogen colonization. In turn, pathogens have evolved effectors to dampen PAMP-triggered signals and thereby attenuate PTI. The plants can only activate a weak response known as basal immunity. Some host plants have evolved resistance $(\mathrm{R})$ proteins to detect the

\footnotetext{
*Correspondence: zhlmou@ufl.edu

${ }^{\dagger}$ Equal contributors

'Department of Microbiology and Cell Science, University of Florida, P.O. Box 110700, Gainesville, FL 32611, USA

Full list of author information is available at the end of the article
}

presence of pathogen effectors, inducing effector-triggered immunity (ETI) [3]. Activation of PTI or ETI leads to the generation of a blend of signal molecules, which move to distal tissues for the establishment of systemic acquired resistance (SAR). SAR is a long-lasting immunity against a broad spectrum of pathogens [4].

Salicylic acid (SA) is a key signal molecule for plant immunity against biotrophic and hemibiotrophic pathogens. It is not only required for the activation of SAR [5,6], but also plays an important role in plant basal immunity and ETI [7-11]. In plants, SA can be made through two metabolic pathways, the phenylalanine ammonia lyase (PAL)mediated phenylalanine pathway and the isochorismate synthase (ICS)-mediated isochorismate pathway. Although knockout of $P A L$ genes significantly reduces SA production [12], the isochorismate pathway is thought to be more important during plant defense [13]. Increasing cellular SA levels induces profound transcriptional changes that

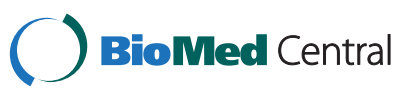


are largely governed by the transcription coactivator NPR1 (nonexpressor of pathogenesis-related $(P R)$ genes). Similarly to SA, NPR1 is not only required for SAR activation, but also plays a significant role in plant basal immunity and ETI [7,14-17]. Interestingly, NPR1 is also a feedback inhibitor of SA biosynthesis. After pathogen infection, npr 1 plants accumulate significantly higher levels of SA [13,17]. Hyperaccumulation of SA causes chlorosis in juvenile leaves and inflorescences of npr1 plants [18]. When grown on media containing high concentrations of SA, npr1 seedlings fail to develop beyond the cotyledon stage, while wild type displays tolerance to SA cytotoxicity $[19,20]$.

In eukaryotic cells, RNA Polymerase II (RNAPII) catalyzes the transcription of protein-encoding genes. The Elongator complex was first identified as an interactor of hyperphosphorylated RNAPII in yeast [21,22], and subsequently purified from mammalian and plant cells $[23,24]$. Elongator consists of six subunits (ELP1-6) with ELP1-3 forming the core subcomplex and ELP4-6 the accessory subcomplex $[25,26]$. Among the six subunits, ELP3 is the catalytic subunit, harboring a C-terminal histone acetyltranferase (HAT) domain and an Nterminal cysteine-rich motif that resembles an ironsulfur $(\mathrm{Fe}-\mathrm{S})$ radical $S$-adenosylmethionine (SAM) domain $[27,28]$. ELP3 alone has intrinsic HAT activity and is capable of acetylating all four histones, whereas the six-subunit holo-Elongator predominantly acetylates lysine-14 of histone $\mathrm{H} 3$ and lysine- 8 of histone $\mathrm{H} 4$ $[22,27]$. Consistently, the levels of acetylated histones H3 and $\mathrm{H} 4$ are reduced in yeast, mammalian, and plant elp mutants [24,27,29]. The radical SAM domain of yeast ELP3 is a structural motif required for the integrity of the complex [30], whereas the archaea Methanocaldococcus jannaschii ELP3 binds and cleaves SAM, a co-substrate involved in methyl group transfers, suggesting that $M$. jannaschii ELP3 may have another catalytic function other than HAT activity [31]. Indeed, a recent study indicated that the radical SAM domain of mouse ELP3, but not the HAT domain, is required for zygotic paternal genome demethylation [32].

Elongator is involved in diverse cellular processes including histone modification, tRNA modification, exocytosis, $\alpha$-tubulin acetylation, and zygotic paternal genome demethylation [27,32,33]. Mutations in yeast Elongator subunits lead to resistance to the zymocin $\gamma$-toxin subunit, sensitivity to salt, caffeine and temperature [21,34,35]. Elongator deficiency in humans causes familial dysautonomia, an autosomal recessive disease, characterized by abnormally low numbers of neurons in the autonomic and sensory nervous systems [36,37]. In addition, Elongator has been shown to regulate tumorigenicity and migration of melanoma cells [38]. In plants, mutations of Elongator subunits result in pleiotropic effects including hypersen- sitivity to abscisic acid, resistance to oxidative stress, severely aberrant auxin phenotypes, disease susceptibility, and altered cell cycle progression [24,39-43].

In order to identify new components in SA signaling, we performed a genetic screen for suppressors of the npr1 mutation based on restoration of SA tolerance on half-strength MS medium supplemented with $0.5 \mathrm{mM}$ SA. A total of 20 gns (green npr1 seedling on SA medium) mutants showing restored SA tolerance have been isolated. We have previously described the gns1 mutant, which harbors a mutation in AtELP2 [42]. Here we report the isolation and characterization of the gns 2 mutant, in which a frameshift mutation was identified in the Arabidopsis Elongator complex subunit 3 (AtELP3). Our results indicate that, like AtELP2, AtELP3 is required for plant basal immunity and ETI but not for SAR, and demonstrate that the HAT and radical SAM domains of AtELP3 are essential for its function in plant immunity.

\section{Results}

The gns2 mutation suppresses hyperaccumulation of SA in $n p r 1$

Similarly to the previously characterized gns1 npr1 [42], the gns 2 npr1 mutant not only exhibited partially restored SA tolerance (Figure 1A), but also accumulated significantly less SA than npr1 after infection by the virulent bacterial pathogen Pseudomonas syringae pv. maculicola (Psm) ES4326 (Figure 1B and C), suggesting that gns 2 suppresses SA hyperaccumulation in npr1. To test whether gns 2 affects pathogen susceptibility, the growth of Psm ES4326 was determined in gns2 npr1 plants. As shown in Figure 1D, while Psm ES4326 grew $\sim 32$-fold more in npr1 than in the wild type, its growth was further increased by $\sim 10$-fold in gns 2 npr 1 plants, indicating that the gns 2 mutation compromises NPR1independent disease resistance.

The leaves of gns 2 npr 1 plants were a lighter shade of green than npr1 (Figure 1E). The gns2 npr1 mutant was backcrossed to nprl three times before further characterization. The $F_{1}$ progeny were not SA tolerant and displayed npr 1 morphology. Of $72 \mathrm{~F}_{2}$ plants, 22 were gns2-like. The 1:3 gns2-like to npr1-like ratio $\left(\mathrm{x}^{2}=\right.$ 1.1852; $\mathrm{P}>0.1$ ), together with the $\mathrm{F}_{1}$ phenotypes fit the expectation that gns 2 is a single, recessive mutation. To determine the co-segregation of gns 2 morphology and $\mathrm{SA}$ tolerance, progeny from $\mathrm{F}_{2}$ plants with npr 1 or gns 2 morphology were examined. Progeny from gns2-like parents were nearly all SA tolerant, while none or only a fraction of the progeny from npr1-like plants were SA tolerant, suggesting that the morphology and SA tolerance of gns 2 co-segregate and are caused by the same mutation or two closely linked mutations. 
A B

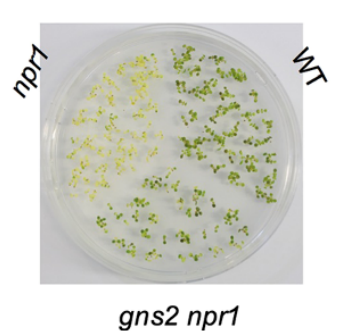

D

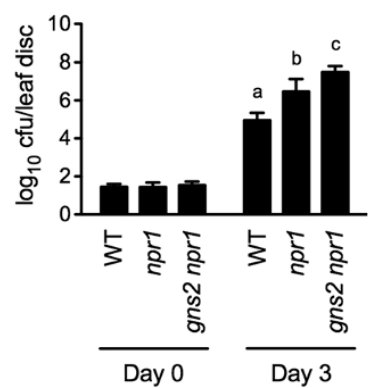

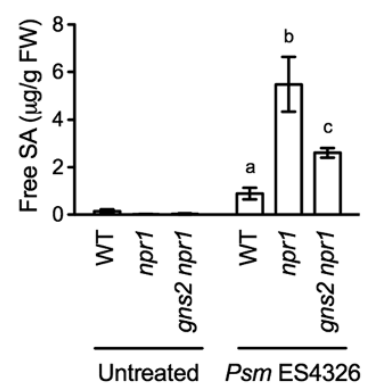

E

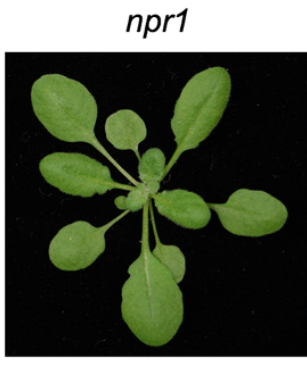

C

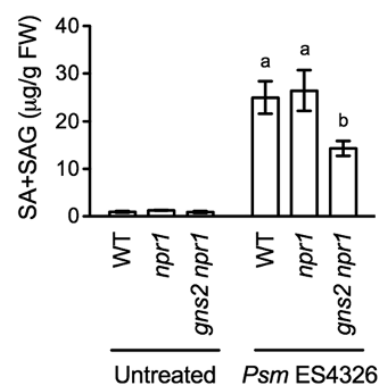

gns2 npr1

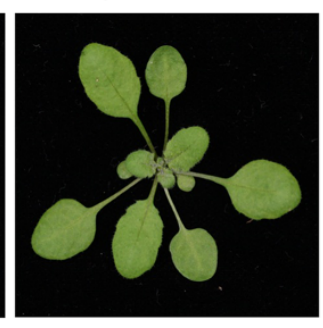

Figure 1 Characterization of the gns2 Mutant. (A) Seeds of wild type (WT), npr1, and gns2 npr1 were placed on half-strength MS agar medium containing $0.26 \mathrm{mM} \mathrm{SA}$. After three days of stratification, the plate was transferred to a growth chamber and photographed ten days later. (B) Four-week-old soil-grown WT, npr1, and gns2 npr1 plants were inoculated with the virulent bacterial pathogen Psm ES4326 $\left(\mathrm{OD}_{600}=0.001\right)$. Twenty-four hours later, the inoculated leaves were collected for SA measurement. Data represent the mean of three independent samples with standard deviation (SD). Different letters above the bars indicate significant differences ( $p<0.05$, Student's $t$-test). (C) Total SA levels in Psm ES4326-infected WT, npr1, and gns2 npr1 plants. The experiment was carried out as in (B). SAG, 2-O-B-D-glucosylsalicylic acid. (D) Leaves of four-week-old soil-grown WT, npr1, and gns2 npr1 plants were inoculated with Psm ES4326 $\left(\mathrm{OD}_{600}=0.0001\right)$. The in planta bacterial titers were determined immediately and three days postinoculation. Cfu, colony-forming units. Data represent the mean of eight independent samples with SD. Different letters above the bars indicate significant differences ( $p<0.05$, Student's $t$-test). (E) Morphology of npr1 and gns 2 npr1 plants. The plants were grown on soil for four weeks before the photos were taken. The gns 2 nprl plant is a lighter shade of green than the npr 1 plant.

The GNS2 locus encodes the Elongator subunit 3

To map the GNS2 locus, homozygous gns 2 npr1, which is in Columbia (Col-0) background, was crossed with the polymorphic ecotype Landsberg erecta (Ler). Linkage analysis of $100 \mathrm{~F}_{2}$ plants with gns 2 morphology placed the GNS2 locus in the middle of the lower arm of chromosome 5, between the molecular markers CIW9 and CIW10 (Figure 2A). Recombination analysis of $1352 \mathrm{~F}_{2}$ light green plants located the GNS2 locus in between markers at the genetic loci At5g50180 and At5g50360 (Figure 2A). One gene within this interval was AtELP3/ELONGATA3(ELO3) (At5g50320) [39], which encodes the third subunit of the Elongator complex. Since gns 2 resembled the previously characterized gns1/Atelp2-5 mutants in SA responses [42], GNS2 might be AtELP3. The AtELP3 coding region was therefore amplified from $g n s 2 n p r 1$ and sequenced. A deletion of a guanine (39 bp from ATG) was detected in the first exon of AtELP3, which allowed the development of a dCAPS marker to genotypically distinguish the mutant from the wild type (Figure $2 \mathrm{C}$ and $\mathrm{B}$ and Additional file 1: Table S1). This mutation caused a frameshift, likely resulting in a truncated and non-functional protein.

To confirm that GNS2 is AtELP3, the AtELP3 cDNA under the control of the constitutive $35 \mathrm{~S}$ promoter of cauliflower mosaic virus was introduced into gns 2 npr 1 . The 35S::AtELP3 transgene complemented all the phenotypes caused by the gns 2 mutation in gns 2 npr 1, including partially restored SA tolerance, light green coloration, reduced SA accumulation after Psm ES4326 infection, and enhanced susceptibility to Psm ES4326 (Figure $2 \mathrm{D}$ to $\mathrm{H}$ ). These results indicate that the mutation in AtELP3 is responsible for the morphological and defense phenotypes of the gns 2 npr 1 plants. The gns 2 mutant was therefore renamed Atelp3-10.

\section{AtELP3 positively contributes to salicylic acid responsiveness}

Compared with npr1, Atelp3-10 npr1 exhibited delayed and reduced expression of PR2 and PR5 during Psm ES4326 infection (Figure 3A). To test the function of AtELP3 in the presence of NPR1, Atelp3-10 npr1 was 


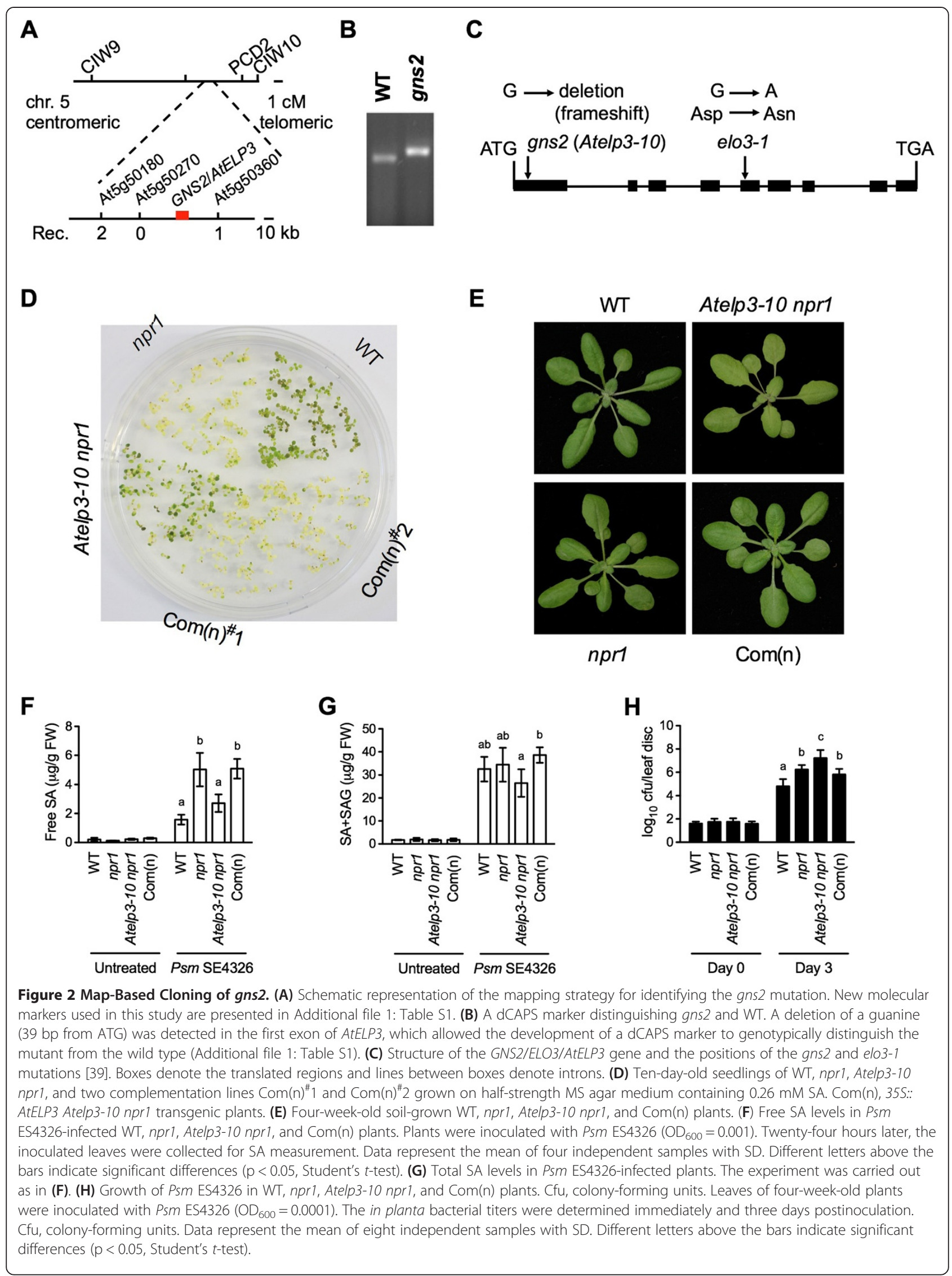




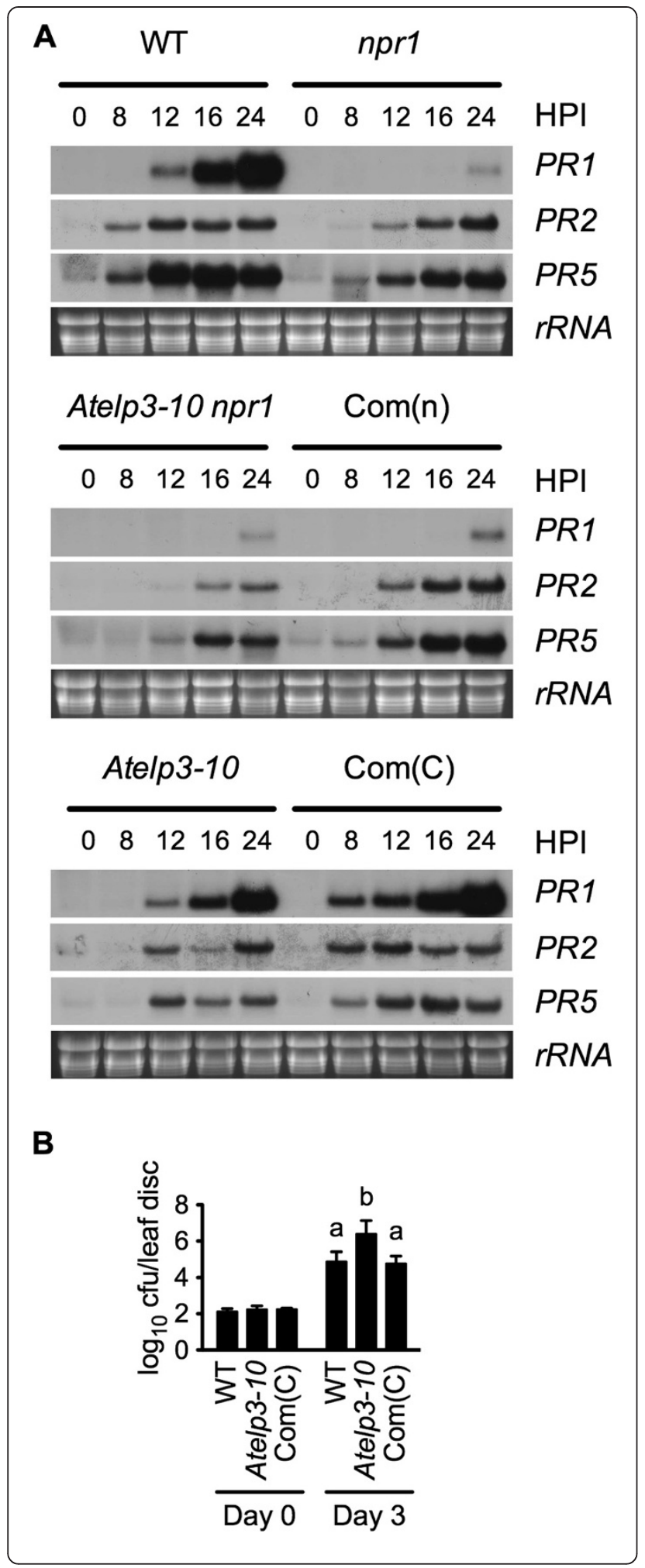

Figure 3 Pathogen-Induced $P R$ Gene Expression in Atelp3-10 npr1 and Atelp3-10 Plants. (A) Expression of PR genes in Psm ES4326-infected WT, npr1, Atelp3-10 npr1, Com(n), Atelp3-10, and Com(C) plants. Com(n), 35s::AtELP3 Atelp3-10 npr1 transgenic plants; Com(C), 35S::AtELP3 Atelp3-10 transgenic plants. HPI, hours postinoculation. Plants were inoculated with PSm ES4326 $\left(\mathrm{OD}_{600}=0.001\right)$. Leaf tissues were collected at the indicated time points after the inoculation. Total RNA was extracted and subjected to RNA gel blot analysis. The RNA samples were run on the same agarose gel and transferred onto the same blotting membrane. The rRNA bands in the ethidium bromide-stained gel were photographed as a loading control prior to blotting. (B) Growth of Psm ES4326 in WT, Atelp3-10, and $\mathrm{Com}(\mathrm{C})$ plants. Cfu, colony-forming units. Leaves of four-week -old plants were inoculated with Psm ES4326 $\left(\mathrm{OD}_{600}=0.0001\right)$. The in planta bacterial titers were determined immediately and three days postinoculation. Data represent the mean of eight independent samples with SD. Different letters above the bars indicate significant differences ( $p<0.05$, Student's $t$-test)

crossed with wild type, and Atelp3-10 single mutants were identified in the segregating $F_{2}$ population based on their morphology (same as the Atelp3-10 npr1 double mutant) and confirmed by the Atelp3-10 and npr1 dCAPS markers (Additional file 1: Table S1). The Atelp3-10 single mutant displayed decreased and/or delayed $P R$ gene expression and enhanced susceptibility to Psm ES4326, and these phenotypes were all completely complemented by a $35 S::$ AtELP3 transgene (Figure $3 \mathrm{~A}$ and $\mathrm{B}$ ), confirming that Atelp3-10 is a loss-of-function mutation.

When treated with SA, Atelp3-10 exhibited delayed PR gene expression (Figure 4A), supporting the conclusion that Elongator plays a role downstream of SA in plant immune responses [42]. On the other hand, SA treatment substantially protected both Atelp3-10 and wild type against Psm ES4326 (Figure 4B). We further analyzed the interaction between SA treatment and genotype with a linear mixed-effects model [44], and found that the Atelp310 mutation did not significantly affect SA-induced resistance against Psm ES4326 ( $\mathrm{p}=0.8285)$.

\section{AtELP3 positively regulates effector-triggered immunity}

To test whether AtELP3, like AtELP2, plays a role in ETI, we examined the expression profiles of nine defense genes that are rapidly induced during ETI $[8,45]$. As shown in Figure 5A, after infection with the ETIinducing bacterial pathogen $P$. s. pv. tomato (Pst) DC3000/avrRpt2, induction of all nine genes was delayed in Atelp3-10 compared with that in the wild type, though expression of some genes eventually reached wild-type levels. Furthermore, Pst DC3000/avrRpt2 growth was $\sim 10$-fold more in Atelp3-10 than in the wild type but lower than in the fully susceptible rps 2 mutant (Figure 5B) [46]. In the double mutant Atelp3-10 npr1, however, Pst DC3000/avrRpt2 growth was $\sim 35$-fold higher than in either Atelp3-10 or npr1, and about sevenfold higher than in rps2 (Figure 5B). These results 

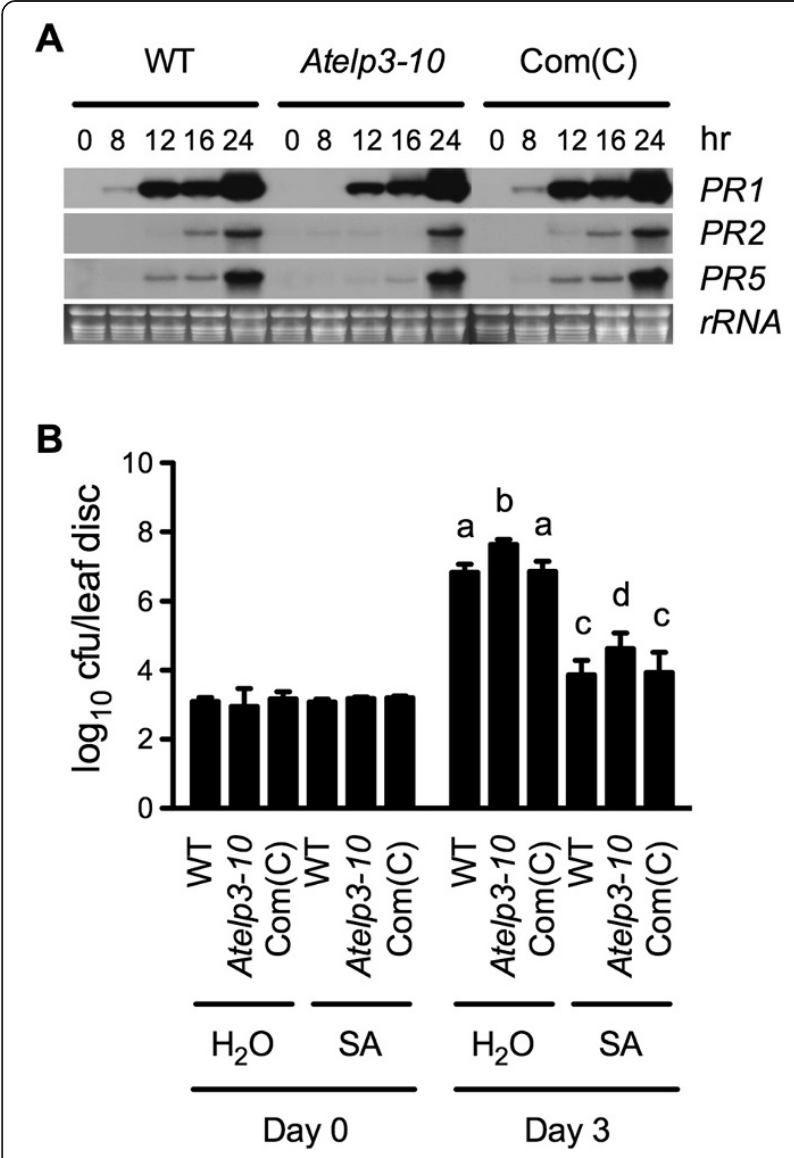

Figure 4 SA-Induced $P R$ Gene Expression and Resistance in Atelp3-10. (A) Expression of PR genes in SA-treated WT, Atelp3-10, and $\mathrm{Com}(\mathrm{C})$ plants. Com(C), 355::AtELP3 Atelp3-10 transgenic plants. Plants were treated with soil drenches of $1 \mathrm{mM} \mathrm{SA}$ water solution or water. Leaf tissue was collected at the indicated time points after the treatment. Total RNA was extracted and subjected to RNA gel blot analysis. The rRNA bands in the ethidium bromide-stained gel were photographed as a loading control prior to blotting. (B) Growth of Psm ES4326 in SA-treated WT, Atelp3-10, and Com(C) plants. Plants were treated with soil drenches of $1 \mathrm{mM}$ SA solution or water. Twenty-four hours later, the plants were inoculated with Psm ES4326 $\left(\mathrm{OD}_{600}=0.001\right)$. The in planta bacterial titers were determined immediately and three days postinoculation. Cfu, colony-forming units. Data represent the mean of eight independent samples with SD. Different letters above the bars indicate significant differences ( $p<0.05$, Student's $t$-test).

are consistent with the conclusion that both Elongator and NPR1 positively regulate ETI [42]. Using a linear mixed-effects model to statistically analyze the data in Figure 5B, we found that the Atelp3-10 and npr1 mutations did not have statistically significant genetic interaction in resistance against Pst DC3000/avrRpt2 $(\mathrm{p}=0.064)$; therefore, AtELP3 and NPR1 appear to function largely independently of each other in ETImediated resistance to Pst DC3000/avrRpt2. However, since the $\mathrm{p}$ value is very close to the significance threshold (0.05), we cannot rule out the possibility of genetic interaction between AtELP3 and NPR1. Indeed, our recent work indicated that AtELP2 regulates both NPR1dependent and -independent defense gene induction [47].

\section{AtELP3 is not required for biological induction of systemic acquired resistance}

We next analyzed the induction of SAR in Atelp3-10 plants. Three lower leaves were injected with $10 \mathrm{mM}$ $\mathrm{MgCl}_{2}$ (mock treatment) or Psm ES4326 (SAR treatment). After two days, SAR treatment-induced gene expression in the upper, untreated leaves was examined. Six genes that are induced during SAR [48] were strongly NPR1-dependent, but only required AtELP3 for their full expression (Figure 6A). Expression levels of these genes were significantly higher in Atelp3-10 plants than in npr1 plants (Figure 6A). When the upper, untreated systemic leaves were challenge-inoculated with Psm ES4326, Atelp3-10 exhibited similar levels of resistance as the wild type (Figure 6B). Using a linear mixed-effects model to statistically analyze the data in Figure 6B, we found that the Atelp3-10 mutation did not have statistically significant effect on SAR treatmentinduced resistance to Psm ES4326 ( $\mathrm{p}=0.279$ ). Therefore, SAR induction restores pathogen resistance to Atelp3-10 plants, which supports the conclusion that Elongator is not required for SAR activation [42].

\section{Both HAT and radical SAM domains of AtELP3 are required for its function in plant immunity}

ELP3 is the catalytic subunit of the Elongator complex, containing a HAT domain and a radical SAM domain. Both domains are required for Elongator's function in yeast, whereas only the radical SAM domain is essential for mouse paternal genome demethylation in zygotes [32]. To test whether the HAT and the radical SAM domain of AtELP3 are required for Elongator's function in plant immunity, we introduced point mutations into the AtELP3 cDNA to generate a HAT domain mutant, in which two conserved tyrosine residues (Y547 and Y548) were changed to alanine, and a radical SAM domain mutant, in which two conserved cysteine residues (C127 and $\mathrm{C} 130$ ) were changed to serine (Figure 7A) [32]. Mutated Atelp3 cDNAs were put under the control of the constitutive $35 \mathrm{~S}$ promoter and transformed into Atelp3-10 and Atelp3-10 npr1 to test the functionality of the HAT and the SAM mutant. Multiple transgenic lines were generated and characterized for both constructs, and one representative transgenic line for each construct was shown in Figure 7. Neither the HAT nor the SAM mutant complemented any of the Atelp3-10 phenotypes, including partially restored SA tolerance (Figure 7B), reduced SA accumulation after Psm ES4326 infection (Figure 7C and D), delayed/decreased defense gene expression (Figure 7E), and enhanced susceptibility to Psm 

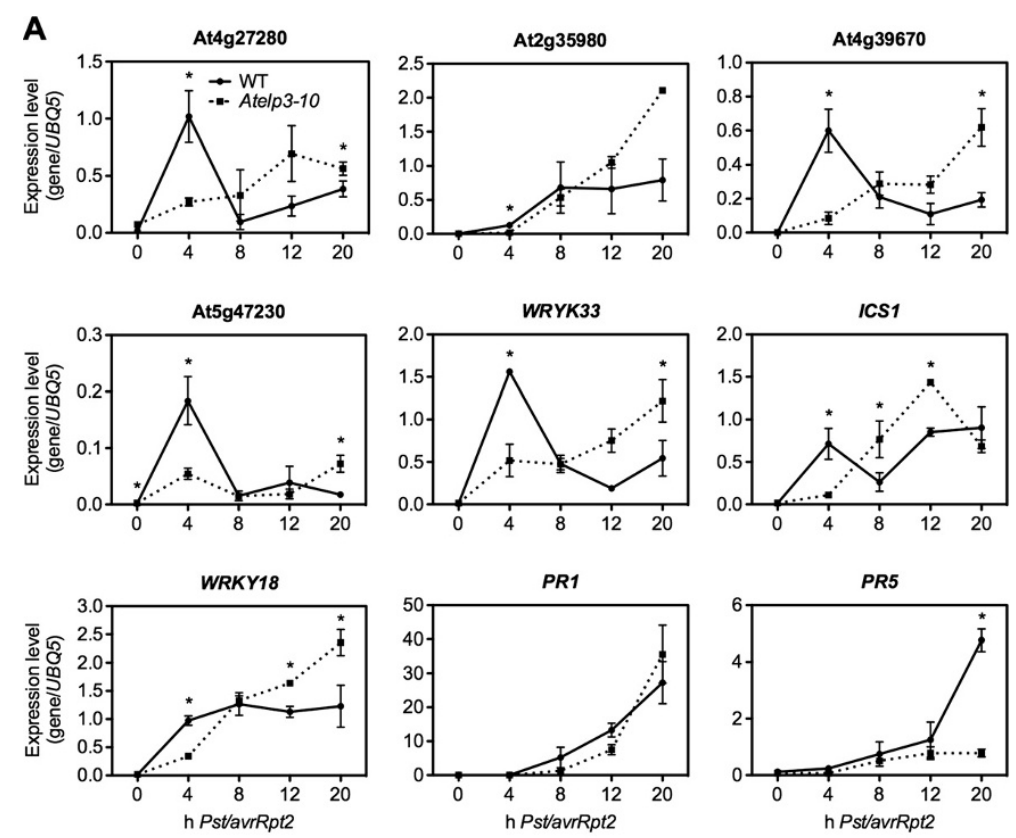

B

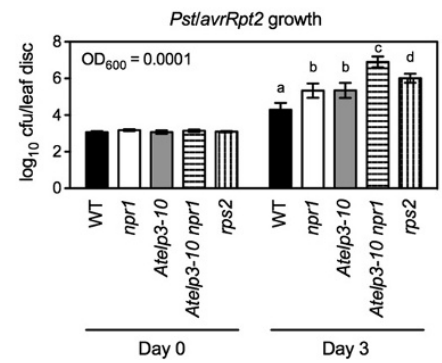

Figure 5 Characterization of ETI in Atelp3-10 Plants. (A) Expression of nine ETI-inducible genes in Pst DC3000/avrRpt2-infected WT and Atelp310 plants. Plants were inoculated with Pst DC3000/avrRpt2 $\left(\mathrm{OD}_{600}=0.001\right)$. Leaf tissues were collected at the indicated time points. Total RNA was extracted and analyzed for the expression of indicated genes using real-time qPCR. The $y$-axes indicate relative expression levels monitored by qPCR. Expression was normalized against constitutively expressed UBQ5. The $x$-axes indicate hours after Pst DC3000/avrRpt2 infection. Data represent the mean of three independent samples with SD. An asterisk $\left(^{*}\right)$ indicates that the expression level of the gene in the WT was significantly different from that in Atelp3-10 ( $p<0.05$, Student's t-test). (B) Growth of Pst DC3000/avrRpt2 in WT, npr1, Atelp3-10, Atelp3-10 npr1, and rps2 plants. Plants were inoculated with Pst DC3000/avrRpt2 $\left(\mathrm{OD}_{600}=0.0001\right)$. The in planta bacterial titers were determined immediately and three days postinoculation. Cfu, colony-forming units. Data represent the mean of eight independent samples with SD. Different letters above the bars indicate significant differences $(p<0.05$, Student's $t$-test).

ES4326 (Figure 7F), indicating that both the HAT and radical SAM domains of AtELP3 are essential for its function in plant immune responses.

\section{Discussion}

The multiprotein complex Elongator functions in diverse biological processes in yeast, animals, and plants likely by accelerating the induction of genes required for development or adaptation to changing environmental conditions. In Arabidopsis, Elongator regulates transcriptional changes induced during pathogen infection $[42,47]$. These transcriptional changes are accompanied by changes in DNA methylation, a hallmark of transcriptional suppression [49], and histone acetylation, which is generally associated with transcriptional activation $[47,50]$. Since the Elongator complex subunit AtELP3 contains both HAT and radical SAM domains, it seems possible that the enzymatic activities of Elongator are directly involved in altering the chromatin status of defense genes to facilitate their induction. Fortuitously, we were able to isolate an Atelp 3 mutant in our genetic screen for suppressors of the npr1 mutation based on restoration of SA tolerance (Figures 1 and 2) [42]. The Atelp3-10 mutant displays similar deficiencies in basal immunity and ETI as Atelp2 (Figures 1D, 2H, and 5B), and like Atelp2 has normal SAR (Figure 6B), suggesting that the Elongator complex itself, but not AtELP2 individually, is the functional unit of action for its role in 


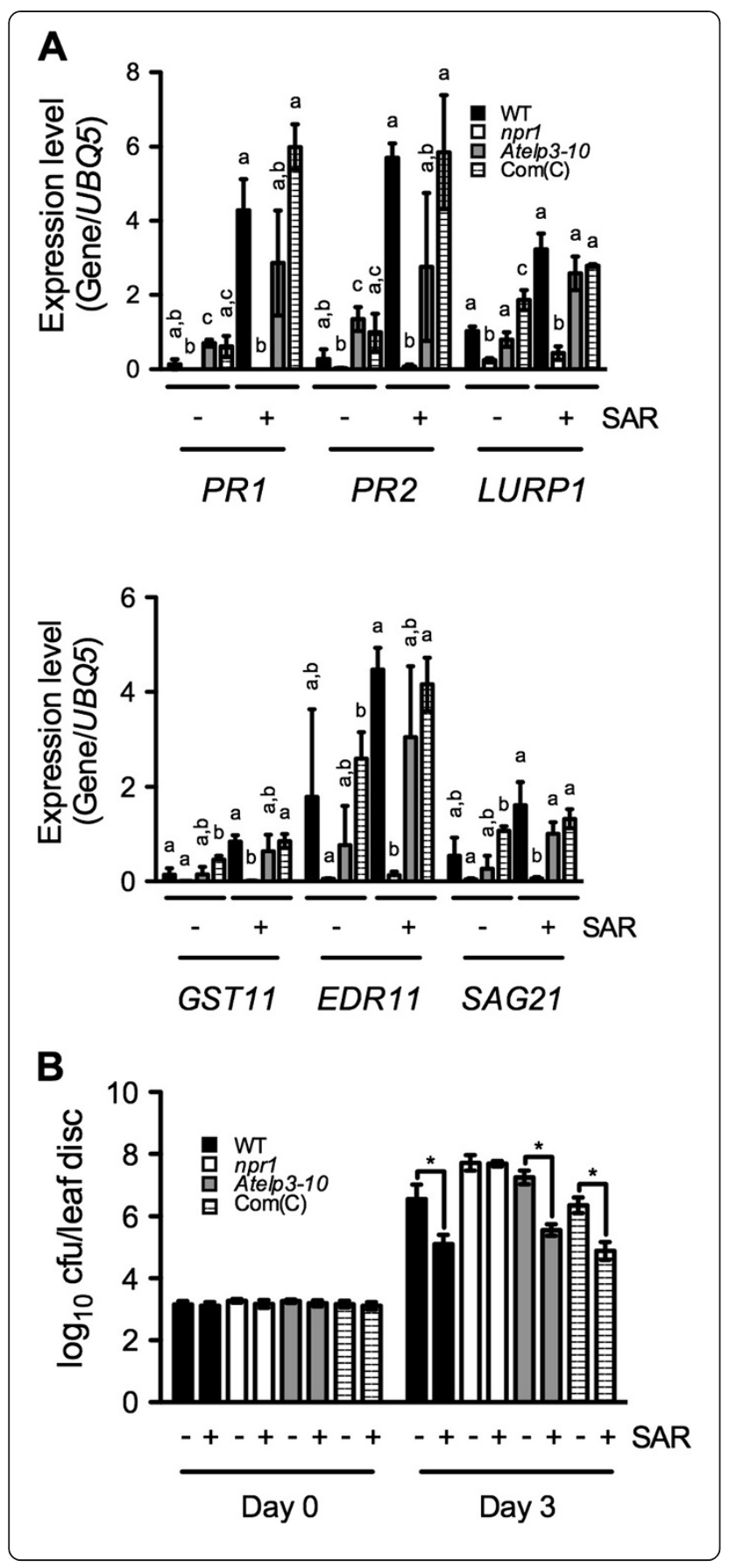

Figure 6 SAR Induction in Atelp3-10 Plants. (A) Expression of six SAR-associated genes in systemic leaves of WT, npr1, Atelp3-10, and Com(C) plants. Com(C), 35S::AtELP3 Atelp3-10 transgenic plants. Three lower leaves on each plant were inoculated with Psm ES4326 $\left(\mathrm{OD}_{600}=0.002\right)(+\mathrm{SAR})$ or mock-treated with $10 \mathrm{mM} \mathrm{MgCl} 2(-\mathrm{SAR})$. Two days later, total RNA was extracted from the upper uninfected/ untreated leaves and analyzed for the expression of indicated genes by real-time $\mathrm{QPCR}$. Expression was normalized against constitutively expressed UBQ5. Data represent the mean of three independent samples with SD. Different letters above the bars indicate significant differences ( $p<0.05$, Student's $t$-test). Note that the comparison was made among WT, npr1, Atelp3-10, and Com(C) for each gene/treatment. (B) SAR induction in WT, npr1, Atelp3-10, and Com(C) plants. Three lower leaves on each plant were inoculated with Psm ES4326 $\left(\mathrm{OD}_{600}=0.002\right)(+\mathrm{SAR})$ or mock-treated with $10 \mathrm{mM} \mathrm{MgCl} 2(-\mathrm{SAR})$. Two days later, two upper uninfected/untreated leaves were challenge-inoculated with PSm ES4326 $\left(\mathrm{OD}_{600}=0.001\right)$. The in planta bacterial titers were determined immediately and three days after challenge inoculation. Cfu, colony-forming units. Data represent the mean of ten independent samples with SD. Psm ES4326 grew significantly less in the SAR-induced WT, Atelp3-10, and Com(C) plants than in the mock-treated plants ( ${ }^{*} A l l p<0.05$, Student's $t$-test).

plant immunity. Indeed, T-DNA insertion mutants of other subunits of the Arabidopsis Elongator complex exhibit Atelp2- and Atelp3-like morphology [39,41]. The function of these subunits in plant immunity will be a subject of further inquiry.

Transgenic complementation of Atelp3-10 with the AtELP3 gene lacking conserved residues in the HAT domain did not restore wild-type levels of SA tolerance, SA accumulation, defense gene induction, and pathogen resistance (Figure 7). Although Elongator's HAT activity has not been demonstrated in plants, it has been proven in yeast [27]. Consistent with this, the levels of acetylated histones are reduced in yeast, mammalian, and plant elp mutants $[24,27,29]$. Previously we found reduced histone acetylation levels at several defense genes in Atelp2, which was correlated with delayed and/or decreased induction of these genes [47]. Taken together, these results suggest that Elongator-dependent histone acetylation may maintain an inducible state at defense loci in Arabidopsis.

Conserved residues in the radical SAM domain proved equally important for AtELP3's function in plant immunity (Figure 7). Although these data demonstrate the importance of the domain, since the enzymatic activity of this domain is currently unknown, the reason for this importance remains elusive. One possibility is that the radical SAM domain is important for the structural integrity of the protein complex, and in yeast, this has been shown to be the case [30]. Alternatively, ELP3 may bind and cleave SAM, as seen in the archaea M. jannaschii [31]. Indeed, a recent study indicated that the radical SAM domain of mouse ELP3, but not the HAT domain, is required for zygotic paternal genome demethylation [32]. 


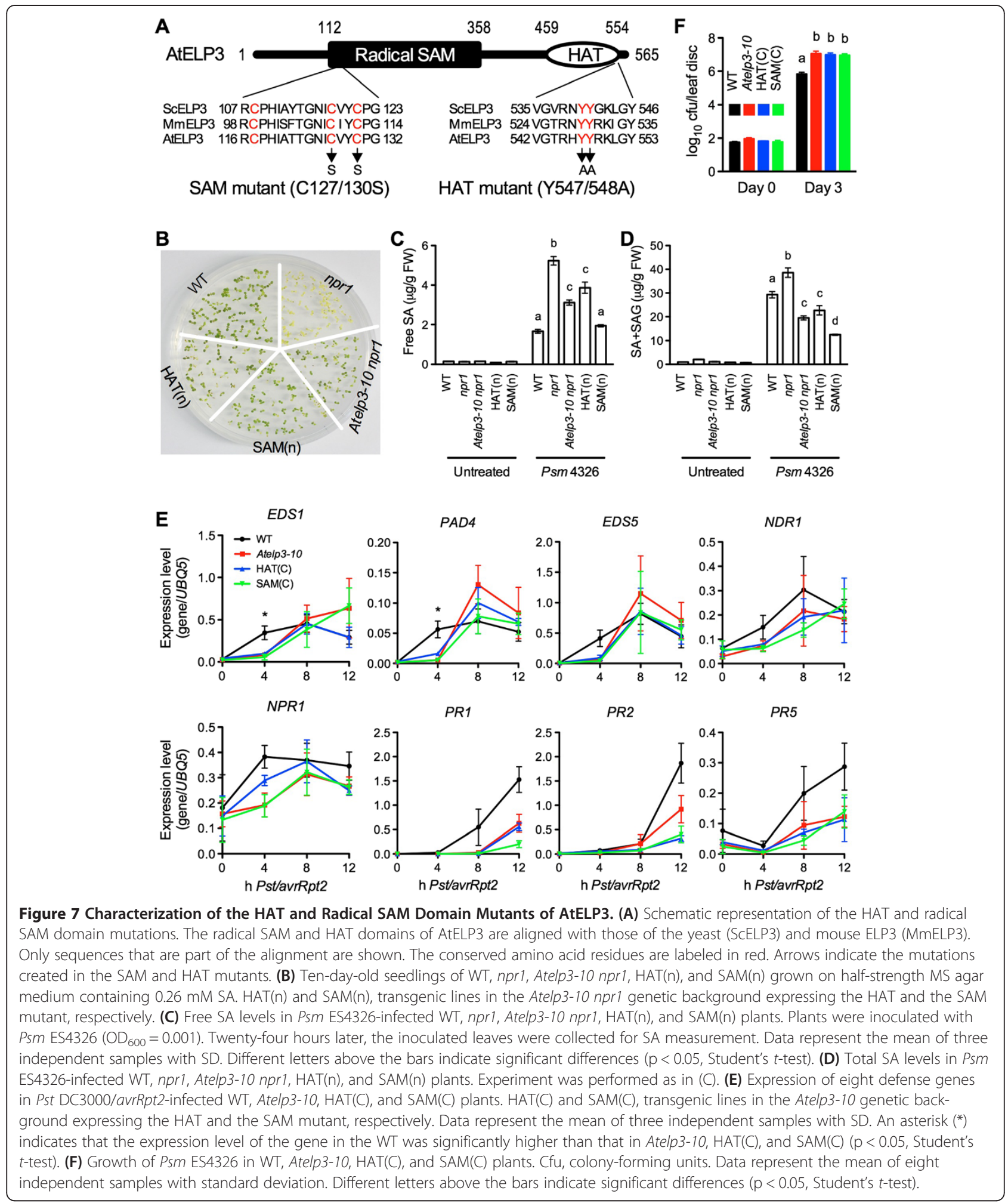

Previously we found altered dynamic DNA methylation changes induced by pathogen infection at some defense loci in Atelp2, which was also correlated with delayed and/or decreased induction [47]. Therefore,
Elongator may also modulate chromatin at defense loci in Arabidopsis through DNA methylation.

Another, non-mutually exclusive possibility is that the role of Elongator in plant immunity depends on its 
function in the modification of wobble uridine tRNA. In yeast and plants, Elongator is essential for these modifications [51,52]. Using overexpression of hypomodified uridine-containing tRNAs, all phenotypes of yeast elp mutants were shown to stem from reduced formation of fully modified tRNAs [53]. Most yeast mutations in the radical SAM domain result in complete loss of the modified nucleoside 5-methoxycarbonylmethyl-2-thiouridine $\left(\mathrm{mcm}^{5} \mathrm{~s}^{2} \mathrm{U}\right)$, while mutations of the HAT domain result in the loss of the majority of $\mathrm{mcm}^{5} \mathrm{~s}^{2} \mathrm{U}$. Loss of $\mathrm{mcm}^{5} \mathrm{~s}^{2} \mathrm{U}$ is closely correlated with the elp mutant phenotypes [53]. In yeast, mutations of conserved amino acids in the SAM domain do not abrogate HAT or RNA binding activity [30]; therefore, for all Elongator roles examined including plant immunity, with the exception of zygotic paternal genome demethylation [32], both the HAT and radical SAM domains of ELP3 are essential, but neither is sufficient. Since plant Elongator is also essential for wobble uridine tRNA modifications [52], it is possible that the immune phenotypes, as well as other elp phenotypes, including altered histone modification and DNA methylation profiles, could be indirect effects of tRNA modification defects in these mutants. Future investigations in plants should address this important question.

Accumulating evidence from diverse organisms is starting to paint a picture where the transcriptional role of Elongator is to facilitate the induction of genes in general. Indeed, previous work performed in our lab and elsewhere has shown that Elongator influences the inducibility of thousands of genes $[35,47,54]$. In this study we established that the HAT and radical SAM domains of the Arabidopsis Elongator subunit AtELP3 are essential for Elongator's immune function. Elongator has also been implicated in diverse stress responses including oxidative and drought stress in Arabidopsis [41]. It would be interesting to determine the role of the HAT and radical SAM domains of AtELP3 in these processes. In this regard, the HAT and radical SAM domain mutants generated in this study provide a useful tool for dissecting the role of these domains throughout development and under diverse stress conditions.

\section{Conclusions}

In this study, we isolated the gns 2 mutant and cloned the GNS2 gene using a map-based cloning approach. We found that GNS2 encodes the Elongator subunit AtELP3. Characterization of gns2/Atelp3-10 indicates that AtELP3 is required for basal immunity and ETI, but not for SAR, suggesting that Elongator as a whole is likely involved in basal immunity and ETI, but not in SAR. Furthermore, we demonstrate that AtELP3's function in plant immunity requires both the HAT and radical SAM domains, which is consistent with a role of
Elongator in facilitating the transcriptional induction of defense genes through alterations to their chromatin.

\section{Methods}

\section{Plant materials and pathogen infection}

The wild type used was the Arabidopsis thaliana (L.) Heynh. Columbia (Col-0) ecotype, and the mutant alleles used were npr1-3 [19] and rps2-201C [46]. Arabidopsis seeds were sown on autoclaved soil (Metro-Mix 200, Grace-Sierra, Malpitas, CA) and vernalized at $4^{\circ} \mathrm{C}$ for three days. Plants were germinated and grown at $\sim 23^{\circ} \mathrm{C}$ under a 16-hr-light/8-hr-dark regime.

Inoculation of plants with Psm ES4326 and Pst DC3000/avrRpt2 was performed by pressure-infiltration with a $1 \mathrm{~mL}$ needleless syringe as described previously [18]. After inoculation, eight infected leaves, one from each plant, were collected for each genotype, treatment or time point to determine in planta growth of the pathogen. For SAR induction, three lower leaves on each plant were inoculated with the virulent bacterial pathogen Psm ES4326 $\left(\mathrm{OD}_{600}=0.002\right)$. Two days later, the upper uninfected systemic leaves were either collected for gene expression analysis or challenge-inoculated with Psm ES4326 $\left(\mathrm{OD}_{600}=0.001\right)$ for resistance test. Ten leaves were collected three days after challenge inoculation to examine the pathogen growth.

\section{RNA analysis}

RNA extraction and RNA gel blot analysis were carried out as described by Cao et al. [14] and Glazbrook et al. [55]. For reverse transcription (RT), total RNA was treated with DNase I (Gibco, BRL) at $37^{\circ} \mathrm{C}$ for $30 \mathrm{~min}$. After inactivation of the DNase, RT was performed using SUPERSCRIPT First-Strand Synthesis System (Gibco, BRL) and $2 \mu \mathrm{g}$ of the DNase-treated RNA in a $20 \mu \mathrm{L}$ reaction. Aliquots of the resulting $\mathrm{RT}$ reaction product were used for real-time quantitative PCR (qPCR), which was performed using SYBR Green protocol (Applied Biosystems, Foster City, CA) with $1 \mu \mathrm{M}$ primers and 0.2 $\mu \mathrm{L}$ aliquot of RT product in a total of $12.5 \mu \mathrm{L}$ per reaction. Reactions were run and analyzed on a MX3000P real-time PCR machine (Stratagene, La Jolla, CA) according to the manufacturer's instructions. The relative quantity of the tested gene is expressed in relation to ubiquitin (UBQ5) using the formula $2^{\wedge}(\mathrm{Ct}\{U B Q 5\}-\mathrm{Ct}$ $\{G E N E\})$, where 2 represents perfect PCR efficiency. We chose $U B Q 5$ as the reference gene for qPCR normalization, because it is one of the most stably expressed genes [56]. All primers used for qPCR in this study have been reported in DeFraia et al. [42].

\section{SA measurement}

SA measurement was done with HPLC as described by Verberne et al. [57]. 


\section{Plasmid construction and plant transformation}

A pair of primers BamH I-AtELP3F1 (5'-CGGGAT CCATGGCGACGGCGGTAGTGATG-3') and Sac I-At ELP2R (5'-CCGAGCTCTCAAAGAAGATGCTTCACC ATGTAAG-3') was used to amplify the coding region of AtELP3 from total cDNA generated by RT. The PCR products were digested with BamH I and Sac I and then ligated into the corresponding sites of the vector pBI1.4 T, resulting in the plamsid pBI1.4 T-35S::AtELP3. Site-directed mutagenesis of the conserved amino acid residues in the HAT and radical SM domains of AtELP3 was performed in the pBI1.4 T-35S::AtELP3 construct using a PCR-based Quick-Change site-directed mutagenesis kit (Stratagene, La Jolla, CA). The primers used for the site-directed mutagenesis of the HAT domain were AtELP3-HATMuF (5'-GTAGGAACCAGACATG CCGCCAGAAAGTTGGGTTATG-3') and AtELP3-HA TMuR (5'-CATAACCCAACTTTCTGGCGGCATGTC TGGTTCCTAC-3'), and for the radical SAM domain mutagenesis, the primers were AtELP3-SAMMuF (5'CGACGGGGAATATATCCGTTTATTCTCCCGGTGGACCTGAC-3') and AtELP3-SAMMuR (5'-GTCAGGT CCACCGGGAGAATAAACGGATATATTCCCCGTCG$\left.3^{\prime}\right)$. The presence of the expected mutations in the resulting construct was verified by DNA sequencing. The plasmids were introduced into the Agrobacterium strain GV3101(pMP90) by electroporation [58], and transformation was performed following the floral dip method [59].

\section{Statistical methods}

Statistical analyses were performed with the data analysis tools (Student's $t$-test: Two Samples Assuming Unequal Variances) in Microsoft Excel of Microsoft Office 2004 for Macintosh. Linear mixed-effects model analysis was performed with the software SAS 9.3. All experiments were repeated at least three times with similar results.

\section{Additional file}

Additional file 1: Table S1. New (d)CAPS markers used in this study

\section{Authors' contributions}

CTD and ZM initiated the research. CTD and YW carried out the molecular experiments. JY helped with data analysis. CTD and ZM wrote the manuscript. All authors critically read and approved the final version of the manuscript.

\section{Acknowledgments}

We thank Dr. Sixue Chen (University of Florida, FL) for access to the HPLC equipment and Dr. Brian J. Staskawicz (University of California, Berkeley, CA) for providing rps2-201C seeds. This work was supported by a grant from the National Science Foundation (IOS-0842716) awarded to Z.M. C.D. was supported by an Alumni Fellowship from the University of Florida.

\section{Author details}

'Department of Microbiology and Cell Science, University of Florida, P.O. Box 110700, Gainesville, FL 32611, USA. ${ }^{2}$ Interdisciplinary Center for

Biotechnology Research, University of Florida, P.O. Box 103622, Gainesville, FL 32610, USA. ${ }^{3}$ Current address: Department of Molecular Genetics, Ohio State University, Columbus, $\mathrm{OH}$ 43210, USA.

Received: 8 April 2013 Accepted: 12 July 2013

Published: 16 July 2013

\section{References}

1. Nurnberger T, Brunner F, Kemmerling B, Piater L: Innate immunity in plants and animals: striking similarities and obvious differences. Immunol Rev 2004, 198(1):249-266.

2. Jones DA, Takemoto D: Plant innate immunity - direct and indirect recognition of general and specific pathogen-associated molecules. Curr Opin Immunol 2004, 16(1):48-62.

3. Jones JD, Dangl JL: The plant immune system. Nature 2006, 444(7117):323-329.

4. Durrant WE, Dong X: Systemic acquired resistance. Annu Rev Phytopathol 2004, 42(1):185-209.

5. Gaffney T, Friedrich L, Vernooij B, Negrotto D, Nye G, Uknes S, Ward E, Kessmann H, Ryals J: Requirement of salicylic acid for the induction of systemic acquired resistance. Science 1993, 261(5122):754-756.

6. Nawrath C, Métraux J-P: Salicylic acid induction-deficient mutants of Arabidopsis express $P R-2$ and $P R-5$ and accumulate high levels of camalexin after pathogen inoculation. Plant Cell 1999, 11(8):1393-1404

7. Rairdan GJ, Delaney TP: Role of salicylic acid and NIM1/NPR1 in racespecific resistance in Arabidopsis. Genetics 2002, 161(2):803-811.

8. Tao Y, Xie Z, Chen W, Glazebrook J, Chang HS, Han B, Zhu T, Zou G, Katagiri F: Quantitative nature of Arabidopsis responses during compatible and incompatible interactions with the bacterial pathogen Pseudomonas syringae. Plant Cell 2003, 15(2):317-330.

9. DebRoy S, Thilmony R, Kwack YB, Nomura K, He SY: A family of conserved bacterial effectors inhibits salicylic acid-mediated basal immunity and promotes disease necrosis in plants. Proc Natl Acad Sci USA 2004, 101(26):9927-9932.

10. Eulgem T, Weigman VJ, Chang HS, McDowell JM, Holub EB, Glazebrook J, Zhu T, Dangl JL: Gene expression signatures from three genetically separable resistance gene signaling pathways for downy mildew resistance. Plant Physiol 2004, 135(2):1129-1144.

11. Tsuda K, Sato M, Glazebrook J, Cohen JD, Katagiri F: Interplay between MAMP-triggered and SA-mediated defense responses. Plant J 2008, 53(5):763-775

12. Huang J, Gu M, Lai Z, Fan B, Shi K, Zhou YH, Yu JQ, Chen Z: Functional analysis of the Arabidopsis $P A L$ gene family in plant growth, development, and response to environmental stress. Plant Physio/ 2010, 153(4):1526-1538.

13. Wildermuth MC, Dewdney J, Wu G, Ausubel FM: Isochorismate synthase is required to synthesize salicylic acid for plant defence. Nature 2001, 414(6863):562-565.

14. Cao H, Bowling SA, Gordon S, Dong X: Characterization of an Arabidopsis mutant that is nonresponsive to inducers of systemic acquired resistance. Plant Cell 1994, 6(11):1583-1592.

15. Delaney TP, Friedrich L, Ryals JA: Arabidopsis signal transduction mutant defective in chemically and biologically induced disease resistance. Proc Natl Acad Sci USA 1995, 92(7):6602-6606.

\section{Competing interests}

The authors declare that they have no competing interests.

\begin{abstract}
AtELP3: Arabidopsis Elongator complex subunit 3; ELO3: ELONGATA3; PAMPs: pathogen-associated molecular patterns; PTI: PAMP-triggered immunity; ETI: effector-triggered immunity; npr1: nonexpressor of SAR: systemic acquired resistance; ICS: isochorismate synthase; PAL: phenylalanine ammonia lyase; RNAPII: RNA Polymerase II; Psm: Pseudomonas syringae pv. maculicola.
\end{abstract}


16. Wang $D$, Amornsiripanitch N, Dong X: A genomic approach to identify regulatory nodes in the transcriptional network of systemic acquired resistance in plants. PLOS Pathog 2006, 2(11):e123.

17. Shah J, Tsui F, Klessig DF: Characterization of a salicylic acid-insensitive mutant (sai1) of Arabidopsis thaliana identified in a selective screen utilizing the SA-inducible expression of the tms 2 gene. Mol Plant Microbe Interact 1997, 10(1):69-78.

18. Clarke JD, Liu Y, Klessig DF, Dong X: Uncoupling PR gene expression from NPR1 and bacterial resistance: Characterization of the dominant Arabidopsis cpr6-1 mutant. Plant Cell 1998, 10(4):557-569.

19. Cao H, Glazebrook J, Clark JD, Volko S, Dong X: The Arabidopsis NPR1 gene that controls systemic acquired resistance encodes a novel protein containing ankyrin repeats. Cell 1997, 88(1):57-63.

20. Kinkema M, Fan W, Dong X: Nuclear localization of NPR1 is required for activation of $P R$ gene expression. Plant Cell 2000, 12(12):2339-2350.

21. Otero G, Fellows J, Li Y, De Bizemont T, Dirac AM, Gustafsson CM, Erdjument-Bromage $H$, Tempst P, Svejstrup JQ: Elongator, a multisubunit component of a novel RNA polymerase II holoenzyme for transcriptional elongation. Mol Cell 1999, 3(1):109-118.

22. Wittschieben BO, Otero G, De Bizemont T, Fellows J, Erdjument-Bromage $H_{\text {, }}$ Ohba R, Li Y, Allis CD, Tempst P, Svejstrup JQ: A novel histone acetyltransferase is an integral subunit of elongating RNA polymerase II holoenzyme. Mol Cell 1999, 4(1):123-128.

23. Hawkes NA, Otero G, Winkler GS, Marshall N, Dahmus ME, Krappmann D, Scheidereit C, Thomas CL, Schiavo G, Erdjument-Bromage H, Tempst P, Svejstrup JQ: Purification and characterization of the human Elongator complex. J Biol Chem 2002, 277(4):3047-3052.

24. Nelissen $H$, De Groeve S, Fleury D, Neyt P, Bruno L, Bitonti MB, Vandenbussche F, Van der Straeten D, Yamaguchi T, Tsukaya H, Witters E, De Jaeger G, Houben A, Van Lijsebettens M: Plant Elongator regulates auxin-related genes during RNA polymerase II transcription elongation. Proc Natl Acad Sci USA 2010, 107(4):1678-1683.

25. Winkler GS, Petrakis TG, Ethelberg S, Tokunaga M, Erdjument-Bromage $H$, Tempst P, Svejstrup JQ: RNA polymerase II Elongator holoenzyme is composed of two discrete subcomplexes. J Biol Chem 2001, 276(35):32743-32749.

26. Li Y, Takagi $Y$, Jiang Y, Tokunaga M, Erdjument-Bromage $H$, Tempst $P$, Kornberg RD: A multiprotein complex that interacts with RNA polymerase II Elongator. J Biol Chem 2001, 276(32):29628-29631.

27. Winkler GS, Kristjuhan A, Erdjument-Bromage $H$, Tempst P, Svejstrup JQ: Elongator is a histone $\mathrm{H} 3$ and $\mathrm{H} 4$ acetyltransferase important for normal histone acetylation levels in vivo. Proc Natl Acad Sci USA 2002, 99(6):3517-3522

28. Chinenov Y: A second catalytic domain in the Elp3 histone acetyltransferases: a candidate for histone demethylase activity? Trends Biochem Sci 2002, 27(3):115-117.

29. Close P, Hawkes N, Cornez I, Creppe C, Lambert CA, Rogister B, Siebenlist U, Merville MP, Slaugenhaupt SA, Bours V, Svejstrup JQ, Chariot A: Transcription impairment and cell migration defects in Elongatordepleted cells: implication for familial dysautonomia. Mol Cell 2006, 22(4):521-531.

30. Greenwood C, Selth LA, Dirac-Svejstrup AB, Svejstrup JQ: An iron-sulfur cluster domain in ELP3 important for the structural integrity of Elongator. J Biol Chem 2009, 284(1):141-149.

31. Paraskevopoulou C, Fairhurst SA, Lowe DJ, Brick P, Onesti S: The Elongator subunit Elp3 contains a Fe4S4 cluster and binds S-adenosylmethionine. Mol Microbiol 2006, 59(3):795-806.

32. Okada Y, Yamagata K, Hong K, Wakayama T, Zhang Y: A role for the Elongator complex in zygotic paternal genome demethylation. Nature 2010, 463(7280):554-558.

33. Creppe C, Malinouskaya L, Volvert ML, Gillard M, Close P, Malaise O, Laguesse S, Cornez I, Rahmouni S, Ormenese S, Belachew S, Malgrange B, Chapelle JP, Siebenlist U, Moonen G, Chariot A, Nguyen L: Elongator controls the migration and differentiation of cortical neurons through acetylation of alpha-tubulin. Cell 2009, 136(3):551-564.

34. Jablonowski D, Frohloff F, Fichtner L, Stark MJ, Schaffrath R: Kluyveromyces lactis zymocin mode of action is linked to RNA polymerase II function via Elongator. Mol Microbiol 2001, 42(4):1095-1105.

35. Krogan NJ, Greenblatt JF: Characterization of a six-subunit holo-Elongator complex required for the regulated expression of a group of genes in Saccharomyces cerevisiae. Mol Cell Biol 2001, 21(23):8203-8212.
36. Anderson SL, Coli R, Daly IW, Kichula EA, Rork MJ, Volpi SA, Ekstein J, Rubin BY: Familial dysautonomia is caused by mutations of the IKAP gene. Am J Hum Genet 2001, 68(3):753-758.

37. Slaugenhaupt SA, Blumenfeld A, Gill SP, Leyne M, Mull J, Cuajungco MP, Liebert CB, Chadwick B, Idelson M, Reznik L, Robbins C, Makalowska I, Brownstein M, Krappmann D, Scheidereit C, Maayan C, Axelrod FB, Gusella JF: Tissue-specific expression of a splicing mutation in the IKBKAP gene causes familial dysautonomia. Am J Hum Genet 2001, 68(3):598-605.

38. Close P, Gillard M, Ladang A, Jiang Z, Papuga J, Hawkes N, Nguyen L, Chapelle JP, Bouillenne F, Svejstrup J, Fillet M, Chariot A: DERP6 (ELP5) and C3ORF75 (ELP6) regulate tumorigenicity and migration of melanoma cells as subunits of Elongator. J Biol Chem 2012, 287(39):32535-32545.

39. Nelissen $H$, Fleury D, Bruno L, Robles P, De Veylder L, Traas J, Micol JL, Van Montagu M, Inze D, Van Lijsebettens M: The elongata mutants identify a functional Elongator complex in plants with a role in cell proliferation during organ growth. Proc Natl Acad Sci USA 2005, 102(21):7754-7759.

40. Chen Z, Zhang H, Jablonowski D, Zhou X, Ren X, Hong X, Schaffrath R, Zhu $\mathrm{JK}$, Gong Z: Mutations in ABO1/ELO2, a subunit of holo-Elongator, increase abscisic acid sensitivity and drought tolerance in Arabidopsis thaliana. Mol Cell Biol 2006, 26(18):6902-6912.

41. Zhou X, Hua D, Chen Z, Zhou Z, Gong Z: Elongator mediates ABA responses, oxidative stress resistance and anthocyanin biosynthesis in Arabidopsis. Plant J 2009, 60(1):79-90

42. Defraia CT, Zhang $X$, Mou Z: Elongator subunit 2 is an accelerator of immune responses in Arabidopsis thaliana. Plant J 2010, 64(3):511-523.

43. Xu D, Huang W, Li Y, Wang H, Huang H, Cui X: Elongator complex is critical for cell cycle progression and leaf patterning in Arabidopsis. Plant J 2012, 69(5):792-808.

44. Diggle PJ, Heagerty P, Liang KY, Zeger SL: Analysis of longitudinal data. 2nd edition. Oxford, England: Oxford University Press; 2002.

45. Navarro L, Zipfel C, Rowland O, Keller I, Robatzek S, Boller T, Jones JD: The transcriptional innate immune response to flg22 Interplay and overlap with Avr gene-dependent defense responses and bacterial pathogenesis. Plant Physiol 2004, 135(2):1113-1128.

46. Kunkel BN, Bent AF, Dahlbeck D, Innes RW, Staskawicz BJ: RPS2, an Arabidopsis disease resistance locus specifying recognition of Pseudomonas syringae strains expressing the avirulence gene avrRpt2. Plant Cell 1993, 5(8):865-875.

47. Wang Y, An C, Zhang X, Yao J, Zhang Y, Sun Y, Yu F, Amador DM, Mou Z: The Arabidopsis Elongator complex subunit2 epigenetically regulates plant immune responses. Plant Cell 2013, 25(2):762-776.

48. Maleck K, Levine A, Eulgem T, Morgan A, Schmid J, Lawton KA, Dangl JL, Dietrich RA: The transcriptome of Arabidopsis thaliana during systemic acquired resistance. Nat Genet 2000, 26(4):403-410.

49. Kass SU, Pruss D, Wolffe AP: How does DNA methylation repress transcription? Trends Genet 1997, 13(11):444-449.

50. Workman $J \mathrm{~L}$, Kingston RE: Alteration of nucleosome structure as a mechanism of transcriptional regulation. Annu Rev Biochem 1998, 67(7):545-579.

51. Huang B, Johansson MJ, Bystrom AS: An early step in wobble uridine tRNA modification requires the Elongator complex. RNA 2005, 11(4):424-436

52. Mehlgarten $\mathrm{C}$, Jablonowski $\mathrm{D}$, Wrackmeyer U, Tschitschmann $\mathrm{S}$, Sondermann D, Jager G, Gong Z, Bystrom AS, Schaffrath R, Breunig KD: Elongator function in tRNA wobble uridine modification is conserved between yeast and plants. Mol Microbiol 2010, 76(5):1082-1094.

53. Chen C, Huang B, Eliasson M, Ryden P, Bystrom AS: Elongator complex influences telomeric gene silencing and DNA damage response by its role in wobble uridine tRNA modification. PLoS Genet 2011, 7(9):e1002258

54. Walker J, Kwon SY, Badenhorst P, East P, McNeill H, Svejstrup JQ: Role of Elongator subunit Elp3 in Drosophila melanogaster larval development and immunity. Genetics 2011, 187(4):1067-1075.

55. Glazebrook J, Rogers EE, Ausubel FM: Isolation of Arabidopsis mutants with enhanced disease susceptibility by direct screening. Genetics 1996, 143(2):973-982.

56. Gutierrez L, Mauriat M, Guenin S, Pelloux J, Lefebvre JF, Louvet R, Rusterucci C, Moritz T, Guerineau F, Bellini C, Van Wuytswinkel O: The lack of a systematic validation of reference genes: a serious pitfall undervalued in reverse transcription-polymerase chain reaction (RT-PCR) analysis in plants. Plant Biotechnol J 2008, 6(6):609-618 
57. Verberne MC, Brouwer N, Delbianco F, Linthorst HJ, Bol JF, Verpoorte R: Method for the extraction of the volatile compound salicylic acid from tobacco leaf material. Phytochem Anal 2002, 13(1):45-50.

58. Shen W-J, Forde BG: Efficient transformation of Agrobacterium spp. by high-voltage electroporation. Nucleic Acids Res 1989, 17(20):8385.

59. Clough SJ, Bent AF: Floral dip: a simplified method for Agrobacteriummediated transformation of Arabidopsis thaliana. Plant J 1998, 16(6):735-743

doi:10.1186/1471-2229-13-102

Cite this article as: DeFraia et al:: Elongator subunit 3 positively regulates plant immunity through its histone acetyltransferase and radical S-adenosylmethionine domains. BMC Plant Biology 2013 13:102.

\section{Submit your next manuscript to BioMed Central and take full advantage of:}

- Convenient online submission

- Thorough peer review

- No space constraints or color figure charges

- Immediate publication on acceptance

- Inclusion in PubMed, CAS, Scopus and Google Scholar

- Research which is freely available for redistribution 